Proceedings

\title{
Aspergillus fumigatus and Candida sp. in the seaside air in the Gdańsk Gulf after an emergency discharge of raw sewage
}

\author{
Małgorzata Michalska' ${ }^{1}$, Monika Kurpas ${ }^{1 *}$, Katarzyna Zorena ${ }^{1}$, Piotr Wąż ${ }^{2}$ and Roman Marks ${ }^{3}$
}

\author{
1 Department of Immunobiology and Environment Microbiology, Medical University of Gdańsk, Gdańsk, \\ Poland, malgorzata.michalska@gumed.edu.pl (M.M.); katarzyna.zorena@gumed.edu.pl (K.Z.) \\ 2 Department of Nuclear Medicine, Medical University of Gdańsk, Gdańsk, Poland; email: pi- \\ otr.waz@gumed.edu.pl (P.W.) \\ 3 Institute of Marine and Environmental Sciences, University of Szczecin, Szczecin, Poland; email:ro- \\ man.marks@usz.edu.pl (R.M.) \\ * Correspondence: monika.kurpas@gumed.edu.pl
}

Publisher's Note: MDPI stays neutral with regard to jurisdictional claims in published maps and institutional affiliations.

Copyright: $\odot 2020$ by the authors. Submitted for possible open access publication under the terms and conditions of the Creative Commons Attribution (CC BY) license (http://creativecommons.org/licenses/by/4.0/).

\begin{abstract}
The aim of this study was to evaluate the presence of potentially pathogenic mold and yeast-like fungi in the air in 5 seaside towns and cities (Hel, Puck, Gdynia, Sopot, and GdańskBrzeźno) between 2014-2017 and in 2018 when an emergency drop of crude sewage took place into the Motława River in Gdańsk. Between 2014 and 2018 from Spring until Summer, 88 atmospheric air samples were collected. In 2018 after an emergency discharge of sewage, a greater but statistically insignificant ( $p>0.05$ ) number of mold and yeast-like fungi was found in the air in Hel, Puck, Sopot, and Gdańsk-Brzeźno compared to 2014-2017 while no breakdown of the sewage treatment plant occurred. Moreover, In 2018 potentially pathogenic molds and yeast-like fungi were detected, including Aspergillus fumigatus, Stachobytrys chartarum and Candida sp. It suggests that the detected species of mold fungi and yeast-like fungi after the failure of the sewage treatment plant can bring a health-related risk for people bathing in the seaside resorts. In the case of a raw sewage drop into the water, it is advised that residents, especially children, the elderly, and immunodeficient people, should be informed of the potentially harmful effects on their health.
\end{abstract}

Keywords: emergency discharge of raw sewage; Gulf of Gdańsk; Aspergillus fumigatus; marine environment; bioaerosol

\section{Introduction}

Bioaerosol is an important airborne fraction, which includes biological elements such as bacteria, viruses, and fungi spores. The presence of these microorganisms has a great impact on the quality of atmospheric air [1]. Studies already have shown that the presence of spores of mold fungi and yeast-like fungi in the air may be the etiological factors of diseases, including pneumonia, allergy, and diabetes mellitus [2,3]. There are many sources of potentially pathogenic and allergenic fungi in bioaerosol. Increased number of mold spores or yeast fungi cells may be associated with heavy rainfall, natural catastrophes, or anthropogenic activity (illegal introduction of municipal wastewater into the marine environment). A special situation that may affect the higher number of fungi in bioaerosol is the controlled introduction a large amounts of raw sewage into the environment. Most often it is related to failures of sewage treatment plants. Studies conducted by Velonakis and Whitman have also shown that mold and yeast-like fungi survive in salt seawater and beach sand for many months $[4,5]$ The presented studies show that an emergency discharge of raw sewage, to the aquatic environment, may cause the appearance of potential pathogenic and allergenic molds and yeast in the air. The aim of the study was to investigate whether the emergency discharge of raw sewage to the Motława River 
(river within the area of Gdańsk city) would have an impact on the mycological quality of the air in coastal regions of the Gulf of Gdańsk.

\section{Material and Methods}

From 2014 to 2018 (spring to summer), 88 samples of air $(0,5 \mathrm{~m} 3)$ were collected in 5 coastal towns (Hel, Puck, Gdynia, Spot, Gdańsk-Brzeźno). All of these spots are located near the coast of the Gulf of Gdańsk. The air samples were collected from $50 \mathrm{~cm}$ above the water surface at a distance of $1 \mathrm{~m}$ from the shoreline towards the Gulf of Gdansk. Air probes were taken using a SAS Super ISO 100 sampler (Italy). The number of molds and yeast fungus was determined by using chloramphenicol medium (YGC) and CHROMagar candida medium. Media plates were incubated at $28^{\circ} \mathrm{C}$ for 5 days. Identification of the detected fungi was based on the appearance of colonies on CHROMagar candida media, and microscopic observations. The number of fungi in the air was converted to the number of colony-forming units (CFU/m3). When applying the impact method, we used the Feller table attached to the manual of the air sampler [6]. The number of colonies of fungi $(\mathrm{CFU} / \mathrm{m} 3)$ was calculated using the equation contained in the publication by Michalska et al. [7]. Statistical analysis of the results was carried out using R software [8]

\section{Results}

3.1. The abundance of molds and yeasts in bioaerosol before, and after the emergency discharge of raw sewage into Motlawa

Our study was conducted in two different periods 2014-2017 - without emergency discharge of raw sewage and year 2018, with emergency disposal of untreated sewage into the Motława River, which flows into the Gulf of Gdańsk. Our results showed a higher number of mold and yeast-like fungi in the air of 4 different coastal cities: Hel, Puck, Sopot, and Gdańsk Brzeźno. In the years 2014-2017, the average number of mold and yeastlike fungi in the seaside town of Hel, Puck, Sopot, and Gdańsk-Brzeźno was, respectively: $17 \pm 19 \mathrm{CFU} / \mathrm{m}^{3}, 36 \pm 18 \mathrm{CFU} / \mathrm{m}^{3}, 16 \pm 8 \mathrm{CFU} / \mathrm{m}^{3}, 20 \pm 10 \mathrm{CFU} / \mathrm{m}^{3}$. In comparison, in the year 2018, when was an emergency discharge of raw sewage, the average number of mold and yeast-like fungi in the seaside town of Hel, Puck, Sopot, and Gdańsk-Brzeźno was, respectively: $260 \pm 494 \mathrm{CFU} / \mathrm{m}^{3}, 194 \pm 90 \mathrm{CFU} / \mathrm{m}^{3}, 228 \pm 195 \mathrm{CFU} / \mathrm{m}^{3}, 205 \pm 180 \mathrm{CFU} / \mathrm{m}^{3}$. The Friedman test was used to study the difference between the number of molds and yeastlike fungi in the years of air sampling. In 2018, in Gdynia, no $\left(0 \pm 0 \mathrm{CFU} / \mathrm{m}^{3}\right) \mathrm{mold}$ and yeast-like fungi were found compared to the years 2014-2017 $\left(34 \pm 35 \mathrm{CFU} / \mathrm{m}^{3}\right)$.

\subsection{Differentiation of molds and yeast in bioaerosol before, and after the emergency discharge of raw sewage into Motlawa}

In the air samples collected in the years 2014-2017 in the towns of Hel, Puck, Gdynia, Sopot, and Gdańsk-Brzeźno, 4 phylum Ascomycota (98.29\%), Basidiomycota (1.52\%) and Zygomycota, Fungi Incertae Sedis were detected $(0.19 \%)$. The same phyla were detected in the air samples collected in the year 2018: Ascomycota (96.17\%), Basidiomycota (1.21\%), and Zygomycota, Fungi IncertaeSedis (2.62\%).

Significant differences in the occurrence of individual species of molds and yeasts in the analyzed periods (2014-2017 and 2018) concerned the presence of potentially pathogenic and allergenic mold and yeast-like fungi were in 2018. In the samples of the seaside air after the emergency discharge of raw sewages were detected the fungi such as Aspergillus fumigatus (1.45\%), Stachybotrys chartarum (4.24\%), Alternaria alternata $(0,29 \%)$, and Candida albicans (27.26\%). These species were not observed in the years 2014-2017. On the other hand in 2014-2017 in contrast to the year 2018, the fungi as Aeurobasiium pullulans $(1,65 \%)$ and Saccharomyces sp. $(2,34 \%)$ were observed. The percentage share of molds and yeast-like fungi in the samples of seaside air is shown in Table 1. 
Table 1. Persistence of fungi in marine bioaerosol in years 2014-2017 and 2018.

\begin{tabular}{|c|c|c|c|c|c|c|c|c|c|}
\hline \multicolumn{5}{|c|}{$2014-2017$} & \multicolumn{5}{|c|}{2018} \\
\hline Kingdom & Phylum & Class & Genus & Species & Species & Genus & Class & Phylum & Kingdom \\
\hline \multirow{6}{*}{ 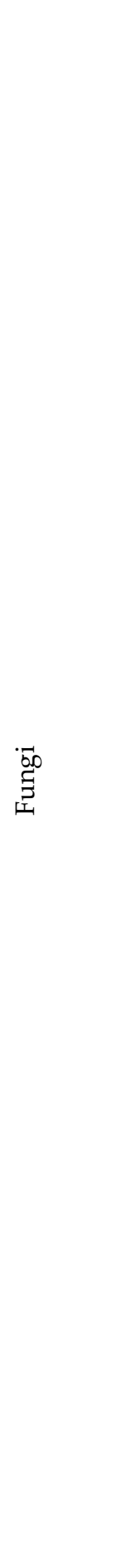 } & \multirow{6}{*}{ 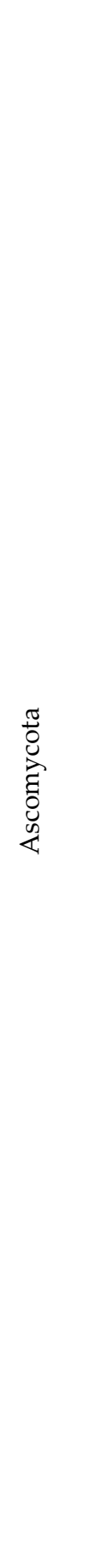 } & & & & 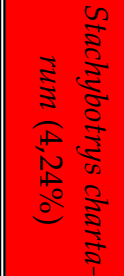 & 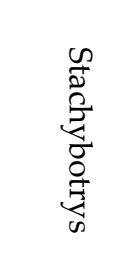 & 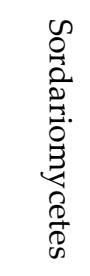 & \multirow{6}{*}{ 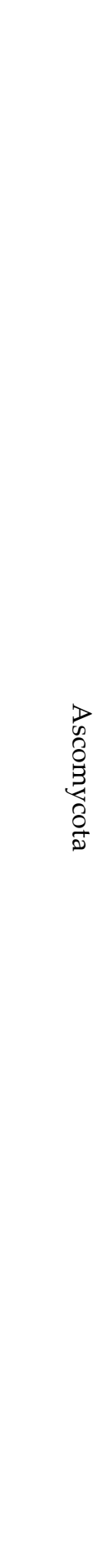 } & \multirow{6}{*}{ 承 } \\
\hline & & & 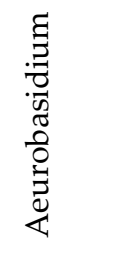 & 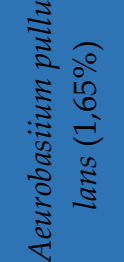 & 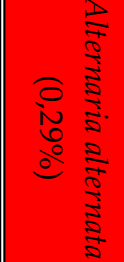 & 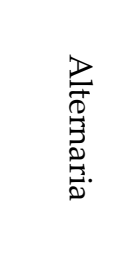 & \multirow{2}{*}{$\begin{array}{l}\nabla \\
0 \\
0 \\
0 \\
0 \\
0 \\
0 \\
0 \\
3 \\
4 \\
0 \\
0 \\
0 \\
0 \\
0\end{array}$} & & \\
\hline & & & $\begin{array}{l}\Xi \\
\Xi \\
0 \\
0 \\
0 \\
0 \\
0 \\
0 \\
\frac{\pi}{U} \\
0\end{array}$ & 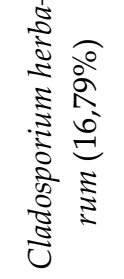 & 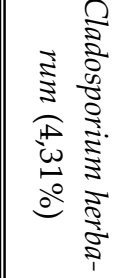 & 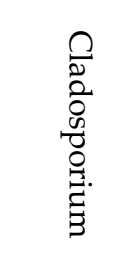 & & & \\
\hline & & 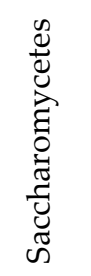 & \multicolumn{2}{|c|}{ 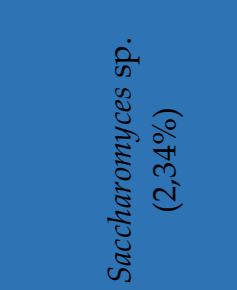 } & 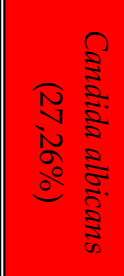 & 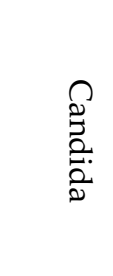 & 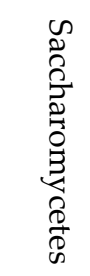 & & \\
\hline & & \multirow{2}{*}{ 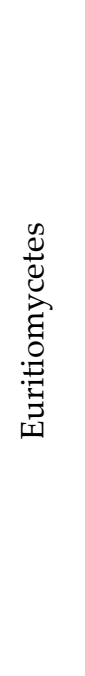 } & 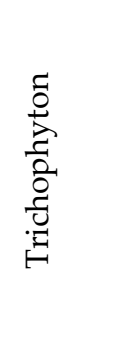 & 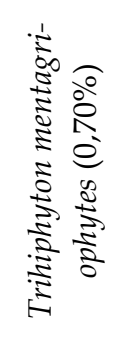 & \multicolumn{2}{|c|}{$\begin{array}{c}-1 \\
3 \\
3 \\
0 \\
0 \\
0 \\
0 \\
0 \\
0 \\
0 \\
0 \\
0 \\
0 \\
0 \\
0 \\
0 \\
0\end{array}$} & \multirow{2}{*}{ 四 } & & \\
\hline & & & 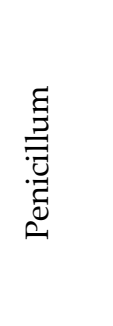 & 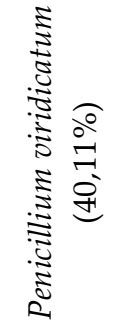 & 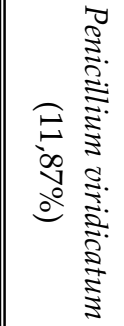 & 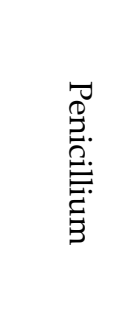 & & & \\
\hline
\end{tabular}




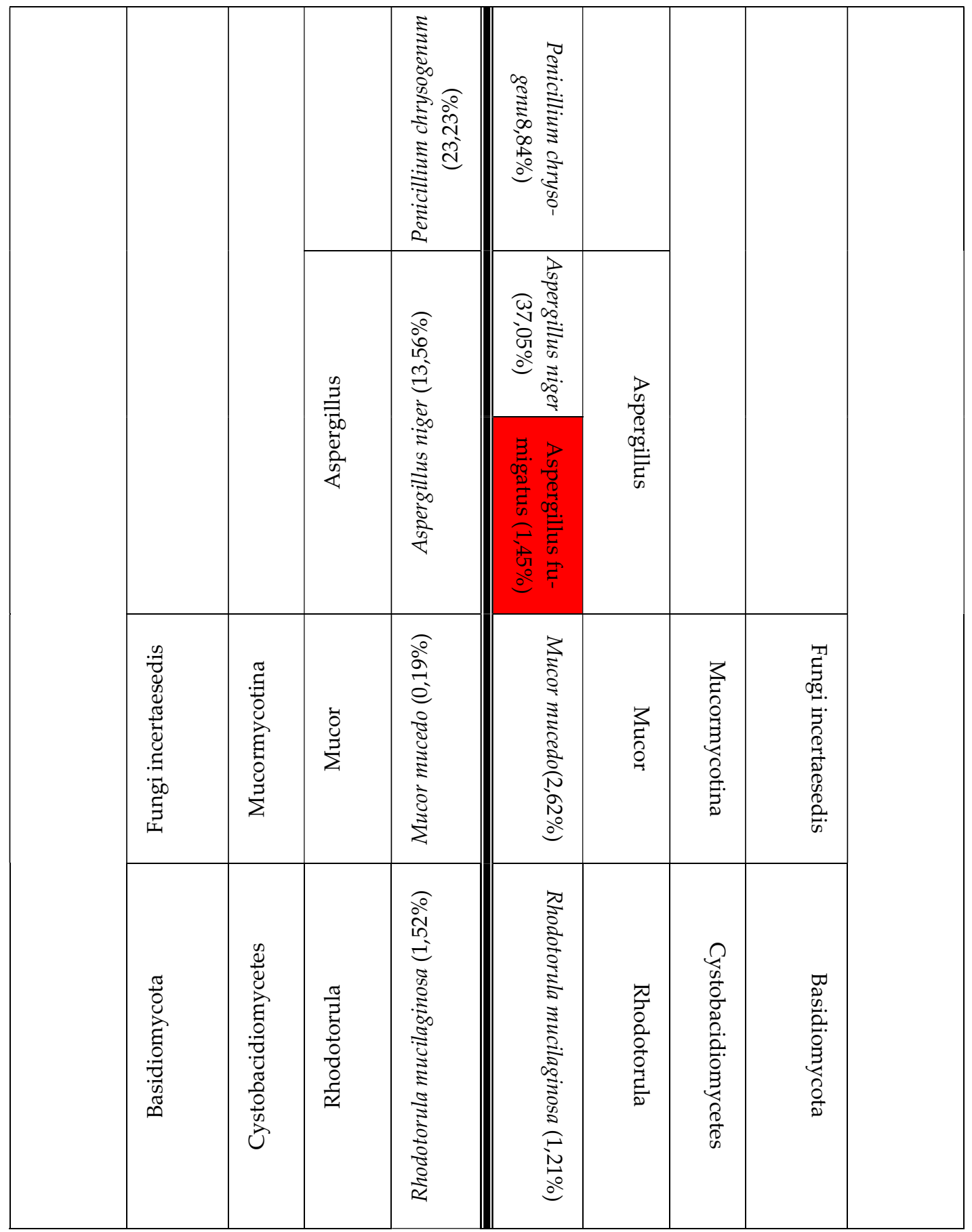

\section{Discussion}

Already published studies indicate that the introduction of raw sewage into the water environment is an important factor contributing to the increase of the number of bacteria and fungi in the bioaerosol in the atmospheric air of coastal regions. $[7,9,10]$. Detection of the potentially pathogenic species as Candida albicans, Stachybotrys chartarum, and Aspergillus fumigatus in the seaside air in 2018 is of key importance. One of the Aspergillus species (which are ubiquitous saprophytes), the Aspergillus fumigatus is extremely dangerous. These fungi are responsible for most of the invasive aspergillosis in immunocompromised people [11]. Research conducted by Warris et. al indicates that in hospital 
conditions, both water and air can be a source of aspergillosis [12]. A particularly vulnerable group of people in the case of aspergillosis caused by Aspergillus fumigatus are patients with cystic fibrosis and asthma [13]. Another pathogenic mold detected in air samples from 2018, is Stachybotrys chartarum. Infections caused by this species are closely related to agricultural land and the environment of flooded buildings. The important factor which has an impact on pathogenesis is toxicogenic metabolites, satratoxins [14]. The next important fungi are yeast: Candida albicans, which is an emerging multidrug-resistant fungal pathogen. Most often this yeast is an etiological factor of invasive candidiasis, with high mortality rates [15]. The presence of these pathogens may in the bioaerosol of seaside air, maybe a significant threat to the elderly and immunosuppressed people. Moreover, the increased values of the total number of fungi in the air samples (as shown in our research) are extremely alarming. We indicate that the number of $\mathrm{CFU} / \mathrm{m}^{3}$ is over ten times higher in case of emergency discharge of raw sewage than in normal situations.

\section{Conclusions}

The result of the study from the 2018 year shows that untreated wastewater associated with emergency disposal to the Gulf of Gdańsk was a likely source of mold and yeastlike fungi in the seaside air. The outcomes were compared with the results obtained in the years 2014-2017, in which the pathogenic species Candida albicans, Stachybotrys chartarum, and Aspergillus fumigatus were not detected. Therefore, after emergency discharges of raw sewage into the aquatic environment, it is necessary to monitor the microbial quality of air, not only in terms of bacteriology but also mycology.

Author Contributions: Conceptualization, M.M. and K.Z.; methodology, M.M, and K.Z.; validation, R.M., P.W., and K.Z.; formal analysis, M.M. and P.W.; investigation, M.M.; statistical analysis, P.W.; data curation, K.Z.; R.M. and P.W.; writing - original draft preparation, M.M. and K.Z.; writing - review and editing, K.Z., M.M., M.K, and P.W.; supervision, K.Z., R.M.

Funding: This research was funded by the Medical University of Gdańsk, grant number (020108/07/780).

Conflicts of Interest: The authors declare no conflict of interest.

\section{References}

Douwes, J.; Thorne, P.; Perce, N.; Heederik, D. Bioaerosol health effect and exposure assessment progress and prospects. Ann. occup. Hyg 2003, 3,187-200

Michalska, M.; Wąż, P.; Zorena, K.; Bartoszewicz, M.; Korzeniowska, K.; Krawczyk, S.; Myśliwiec, M.; Potential effects of microbial air quality on the number of new cases of diabetes type 1 in children in two regions of Poland: a pilot study. Infect. Drug Resist. 2019, 12, 2323-2334

Zhang, I.; Pletcher, S.D.; Goldberg, A.N.; Barker, B.M.; Cope, E.K. Fungal Microbiota in Chronic Airway Inflammatory Disease and Emerging Relationships with the Host Immune Response. Front. Microbiol. 2017, 8, 2477

Velonakis E., Dimitriadi, D., Papadogiannakis, E., Vatopoulos, A., 2014. Present status of effect of microorganisms from sand beach on public health. J. Coast. Life Med. 2, 746-756.

Whitman R, Harwood VJ, Edge TA, et al. Microbes in Beach Sands: Integrating Environment, Ecology, and Public Health. Rev Environ Sci Biotechnol. 2014;13(3):329-368. doi:10.1007/s11157-014-9340-8

Feller W. An Introduction to Probability Theory and Its Applications - Vol. II. John Wiley and Sous Inc., New York, 1950

Michalska, M.; Zorena, K.; Bartoszewicz, M. Analysis of fecal bacteria isolated from air and seawater samples following an emergency sewage discharge into the Gulf of Gdansk in 2018 - a preliminary study. Int. Marit. Health 2019, 70, 239-243

Core Team R: A Language and Environment for Statistical Computing R Foundation for Statistical Computing, Vienna, Austria. 2018, Available online at https://www.R-project.org/

Michalska, M.; Bartoszewicz, M.; Cieszyńska, M.; Nowacki, J.; Bioaerosols on Tri-city (Gdańsk-Sopot-Gdynia) beaches. Int. Marit. Health 2010, 61, 41-43

Brandão, J.; Albergaria, I.; Albuquerque, J.; José, S.; Grossinho, J.; Ferreira, F.C.; et al. Untreated sewage contamination of beach sand from a leaking underground sewage system. Sci. Total Environ 2020, 740, 140237

Dagenais, T.R.T.; Keller, N.P. Pathogenesis of Aspergillus in invasive aspergillosis, Clin. Microbiol. Rev. 2009, 22, 447-465

Warris, A.; Klaassen, C.H.H.; Meis, J.F.G.M.; Ruiter, T.; Valk, H.A.; Abrahamsen, T.G.; Gaustad, P.; Verwij, P.E.; Molecular epidemiology of Aspergillus fumigatus recovered from the water, air, and patients shows two clusters of genetically distinct strains. J. Clin. Microbiol. 2013, 41, 4101-4106 
Ghosh, S.; Hoselton, S.A.; Schuh, J.M.; Allergic inflammation in Aspergillus fumigatus induced fungal asthma. Curr. Allergy Asthma Rep. 2015, 59, 1-11

Johanning, E.; Biagini, R.; Hull, D.; Morey, P.; Jarvis, B.; Landbergis, P. Health and immunology study following exposure to toxigenic fungi (Stachrybotrys chartarum) in a water-damaged office environment. Int. Arch. Occup. Environ. Health 1996, 69, 207-218

Dadar, M.; Tiwari, R.; Karthik, K.; Chkraborty, S.; Shahali, Y.; Dhama, K.; Candida albicans - biology, molecular characterization, pathogenicity, and advances in diagnosis and control - an update. Microb. Pathog. 2018, 117: 128-138 